\title{
Are there multiple channels through which we connect with beauty and excellence?
}

\author{
Güsewell, Angelika ; Ruch, Willibald
}

\begin{abstract}
This research answers the question whether there are multiple channels through which we connect with beauty and excellence, and thus contributes to the understanding of the structure of appreciation. Two models were examined: the appreciation of beauty and excellence (ABE) model [Haidt, J., Keltner, D. (2004). Appreciation of beauty and excellence [awe, wonder, elevation]. In C. Peterson M.E.P. Seligman (Eds.). Character strengths and virtues (pp. 537-551). New York, NY: Oxford University Press], and the engagement with beauty model [Diessner, R., Solom, R., Frost, N.K., Parsons, L., Davidson, J. (2008). Engagement with beauty: Appreciating natural, artistic, and moral beauty. The Journal of Psychology: Interdisciplinary and Applied, 142, 303-329]. Study 1 describes the development and initial validation of the ABE Test (ABET), which assesses the types of appreciation included in Haidt and Keltner's (2004) model. In study 2, the ABE subscale of the Values In Action Inventory of Strengths [VIA-IS; Peterson, C., Park, N., Seligman, M.E.P. (2005). Assessment of character strengths. In G.P. Koocher, J.C. Norcross, S.S. Hill III (Eds.), Psychologists' desk reference (Vol. 3, pp. 93-98). New York, NY: Oxford University Press], the Engagement with Beauty Scale (Diessner et al., 2008), and the ABET were included in a structural equation modeling analysis. Results suggested a new model encompassing the two previous ones, and distinguishing between natural beauty, artistic beauty, and non-aesthetic goodness.
\end{abstract}

DOI: https://doi.org/10.1080/17439760.2012.726636

Posted at the Zurich Open Repository and Archive, University of Zurich

ZORA URL: https://doi.org/10.5167/uzh-66395

Journal Article

Accepted Version

Originally published at:

Güsewell, Angelika; Ruch, Willibald (2012). Are there multiple channels through which we connect with beauty and excellence? The Journal of Positive Psychology, 7(6):516-529.

DOI: https://doi.org/10.1080/17439760.2012.726636 
This manuscript was published as:

Güsewell, A., \& Ruch, W. (2012). Are there multiple channels by which to connect with beauty and excellence? Journal of Positive Psychology, 7, 516-529. doi: 10.1080/17439760.2012.726636 


\section{Are there Multiple Channels through which we Connect with Beauty and}

\section{Excellence?}

Angelika Güsewell and Willibald Ruch

University of Zurich, Zurich, Switzerland

Author Note

Angelika Güsewell, Department of Psychology, University of Zurich,

Switzerland; Willibald Ruch, Department of Psychology, University of Zurich, Switzerland.

This paper is based on a $\mathrm{PhD}$ Thesis of the first author, supervised by the second author. The authors wish to thank Rhett Diessner for helpful comments on an earlier version of this manuscript.

Address correspondence to Angelika Güsewell, Section on Personality and Assessment, Department of Psychology, University of Zurich, Binzmühlestrasse 14/7, 8050 Zurich, Switzerland. E-mail: angelika.gusewellschaub@uzh.ch 


\section{Abstract}

This research answers the question whether there are multiple channels through which we connect with beauty and excellence, and thus contributes to the understanding of the structure of appreciation. Two models were examined: the appreciation of beauty and excellence model (Haidt \& Keltner, 2004), and the engagement with beauty model (Diessner, Solom, Frost \& Parsons, 2008). Study 1 describes the development and initial validation of the Appreciation of Beauty and Excellence Test (ABET), which assesses the types of appreciation included in Haidt and Keltner's (2004) model. In study 2, the appreciation of beauty and excellence subscale of the Values In Action Inventory of Strengths (VIA-IS; Peterson \& Seligman, 2005), the Engagement with Beauty Scale (EBS; Diessner et al., 2008), and the ABET were included in a structural equation modeling analysis. Results suggested a new model encompassing the two previous ones, and distinguishing between natural beauty, artistic beauty, and non-aesthetic goodness. Keywords: appreciation of beauty and excellence, engagement with beauty, positive psychology, character strengths 
Though we travel the world over to find the beautiful, we must carry it with us, or we find it not. Ralph Waldo Emerson (1941, p.121)

\section{Are there multiple channels through which we connect with beauty and excellence?}

\section{Introduction}

Aesthetic sensitivity and the human tendency to experience strong emotional responses to art, beauty and excellence have been studied since ancient times in the context of philosophy and religion. Theorists concentrated mainly on characteristics of the objects that elicited these feelings, less on characteristics of those who appreciated them. The same tendency continued in the psychological approach to aesthetics. The main focus of research was on the objective features of different stimuli or objects of art. Little research examined individual differences in the perception of and reactions to beauty, until humanistic psychology - with its idea of an innate and powerful emotional response to beauty and excellence - brought in new perspectives on the question. Maslow (1964) studied individual differences in the degree to which people were open to peak experiences and to beauty. Costa and McCrae (1992) described openness to aesthetics as a "deep appreciation for art and beauty" (p. 17). Openness to peak experiences and beauty (Maslow, 1964), and openness to aesthetics (Costa and McCrae, 1992) are both one-dimensional. More recently, within the context of positive psychology, two multi-dimensional (i.e. structural) models of the sensitivity to the beautiful and to the good were proposed (Figure 1).

Insert Figure 1 about here 
Figure 1 shows (a) the appreciation of beauty and excellence-model of Haidt and Keltner (2004), which combines the sensitivity to beauty in the physical world with the sensitivity to excellence in the social world (in turn sub-divided into the sensitivity to skills or talent, and virtue or moral goodness), and (b) the engagement with beautymodel of Diessner, Solom, Frost, Parsons, and Davidson (2008), who posited a specific responsiveness to natural, artistic and moral beauty.

\section{Two models of the sensitivity to the good and beautiful}

Peterson and Seligman (2004) introduced the character strength appreciation of beauty and excellence into their classification of good character, which encompasses six universal virtues and 24 more specific character strengths. Appreciation of beauty and excellence (or simply appreciation) denotes the ability to "find, recognize, and take pleasure in the existence of goodness in the physical and social worlds" (Haidt \& Keltner, 2004, p. 537). According to Haidt and Keltner (2004) beauty is experienced as a response to goodness in the physical world - that is to the visual and auditory environment - whereas excellence is experienced when faced with goodness in the social world: exceptional skills or talents of other people, and displays of virtue or moral goodness. Therefore, appreciation of beauty and excellence means the sensitivity to three different types of goodness, namely (a) physical beauty, (b) skills or talent, and (c) virtue or moral goodness (Figure 1a).

Diessner et al. (2008) proposed another model of the sensitivity to beauty, labeled engagement with beauty. In this model, the difference between goodness and beauty, especially the difference between moral goodness and beauty, is crucial, and lies in the emotional involvement of the observer. An act of moral goodness may be cognitively experienced as such, even without emotional involvement; however, it becomes an act of moral beauty if the observer feels moved and elevated. The act is the 
same, but the subjective, emotional reaction is different. According to Diessner et al. (2008), this distinction between goodness and beauty, may also be applied to human made objects, or nature. Engagement with beauty comprises the sensitivity to artistic, moral, and natural beauty (Figure 1b).

\section{Open questions}

Haidt and Keltner (2004) raised a question which is essential for the multi-dimensional model of appreciation they describe, namely the question of whether or not it makes conceptual sense to group the sensitivity to different types of goodness together. They pointed out that empirical research is needed to determine if they "do in fact cluster together in individuals" (p. 538), that is, if a person who is sensitive to physical beauty also has the ability to recognize and take pleasure in skills or talent, and virtue or moral goodness. Alternatively, it may be that people high in appreciation of beauty and excellence rather have a specific sensitivity to one of these three types of goodness. The VIA-IS appreciation of beauty and excellence (ABE) subscale (Peterson \& Seligman, 2004), which comprises items relating to beauty in the physical world, and to moral goodness points this direction, as only a total score is computed. However, none of the 10 items of the ABE addresses the sensitivity to skills and talents. A distinct measure of this sensibility would allow further examination of whether and which of the three kinds of appreciation might be grouped together. This question is not only of theoretical interest, but also has practical implications. If empirical research shows that "multiple channels by which people can connect to excellence around themselves and create enriched and awe-filled lives" (Haidt \& Keltner, 2004, p. 538) actually do exist, appreciation becomes accessible even to those who have little exposure to literature, classical music, or art museums. If furthermore the sensitivities to different types of goodness prove to be related, engaging emotionally in one of them might have an 
impact on the other two. And this, in turn, could lead to the development of new pedagogical curricula or positive psychology interventions.

Diessner et al. (2008) showed that the three subscales of their Engagement with Beauty Scale (EBS) were correlated, but distinct, thus giving first empirical evidence for the multi-dimensionality of appreciation. But their findings rely on one single questionnaire, and would need to be confirmed by a different type of measure. In fact, as both the ABE and the EBS are self-report questionnaires, they share the problems of a response pattern which might be influenced by social-desirability, or by intrapersonal intelligence (i.e. the knowledge people have of themselves). Therefore, an open question is, whether and to what extent a more objective measure correlates with self-report measures of appreciation. In addition, further statistical analyses are needed to determine if correlation patterns found within or among the self-report instruments can be reproduced with a more objective test.

Finally, the models of Haidt and Keltner (2004) and Diessner et al. (2008) are overlapping but not identical. Both models hypothesize a second-order factor of general sensitivity to the beautiful and good, and both models are three-dimensional; they share a dimension of artistic beauty, and a dimension of moral beauty or goodness. Additionally, appreciation of beauty and excellence posits a distinct skills and talent dimension, whereas engagement with beauty encompasses natural beauty as a third, separate dimension. These similarities and partial overlap, as well as the differences, raise the question of how the two models relate to each other.

\section{Aims of the research}

Following these thoughts, the aim of our research was threefold. First, we aimed to develop a more objective (stimulus-based instead of self-report) instrument based on the structure of appreciation hypothesized by Haidt and Keltner (2004) to assess 
appreciation of beauty and excellence. This new instrument would not only address physical and moral beauty, but also skills and talents. Second, we intended to examine the convergent validity of this new instrument with the two existing ones. Finally, we meant to check the structure of the sensitivity to the beautiful and the good, that is to assess if one or both of the two models - developed by Haidt and Keltner (2004) and Diessner et al. (2008) - can be empirically confirmed, or if a different or a combined model fits the data best. This last step should then allow an answer to the question of whether or not there are "multiple channels by which people can connect with beauty and excellence around them and create enriched and awe-filled lives" (Haidt \& Keltner, 2004, p. 538).

\section{Study I: Development of the ABET}

The aim of this first study was to (a) develop a stimulus-based test assessing the sensitivity to physical beauty, skills and talents, and virtue or moral goodness, (b) examine its psychometric properties (i.e. corrected item-total-correlations, exploratory factor analysis, and internal consistencies, and (c) use this newly created test to study whether, and to what extent, the three sensitivities are correlated.

\section{Method}

\section{Participants}

The sample consisted of $\mathrm{N}=246$ German-speaking participants (172 women, 74 men) aged 18 to 79 years $(M=46.86 ; \mathrm{SD}=13.24)$. Education ranged from compulsory education (high school) to University degree, $55 \%$ of the participants were married, 45 $\%$ lived alone, and 79\% were employed or self-employed. Volunteers were recruited through flyers, direct emailing, announcements on Internet sites and short contributions about positive psychology in magazines.

Materials and procedure 
Based on the structure of appreciation hypothesized by Haidt and Keltner (2004), a 30item instrument called the Appreciation of Beauty and Excellence Test (ABET) was developed. The ABET comprises pictures, music excerpts, texts to read and texts to listen to, as well as video clips. The structure of appreciation, together with the ABET items are presented in Appendix 1.

According to Haidt and Keltner (2004), physical beauty encompasses visual and auditory beauty. Therefore paintings and musical excerpts (6 items each) were included in the ABET, together with short poems (6 items), which were read by professional actors. Music excerpts, paintings and poems were selected in order to be as diverse as possible. Other areas of physical beauty, such as natural beauty and sexual beauty, were not included, as it was expected that reproductions of paintings or recordings of music would elicit appreciation more easily and "naturally" in the context of an online survey than pictures of nature, or human bodies. Six short stories about people displaying moral goodness or moral beauty were selected from textbooks for ethics classes on college level, and adapted to the needs of the study. Some of these short stories were about "everyday moral goodness" whereas others described extreme situations (e.g. hiding Jewish people during World War II). Following Haidt and Keltner (2004), who described skills and talents as "non-aesthetic forms of excellence such as might be demonstrated by athletes or jugglers" (p. 539), three short video clips of persons displaying great artistic, athletic or acrobatic skills were chosen, together with three short texts describing brilliant persons with particular intellectual or professional talents.

These 30 ABET items were presented online. Each was to be rated on two 5point Likert scales (ranging from $1=$ not at all, to $5=$ absolutely) indicating how much someone experienced "beauty" and "excellence". Correlations between these two ratings proved to be very high for the music, painting and lyric items, that is for items 
relating to goodness in the physical world (.79 to .86$)$, high for the virtue and moral goodness items (.60) and medium for to the skills and talent items (.42). These correlations did not support Haidt and Keltner's (2004) assumption that goodness in the physical world would mainly elicit the experience of beauty, and goodness in the social world the experience of excellence. They rather suggested that the experiences of beauty and excellence were related to different degrees, depending on the nature of the respective stimulus: closely related for works of art or pieces of music, more loosely for moral goodness, and hardly for skills and talents. Language use probably explains this finding. By German word usage, "beauty" and "excellence" apply equally well to works of art, whereas for the description of moral goodness, the term "beauty" is much more common, and for skills or talents only the term "excellence" in use. Therefore, participants required to rate the "beauty" of an athletic, acrobatic, or intellectual skill might have concentrated on the beauty of the visual or musical aspects of the videoclips, rather than on the beauty of the skill or talent itself. Or participants asked to indicate the "beauty" and "excellence" experienced while listening to a piece of music might not have perceived the nuance between these two terms. It was therefore decided to retain only one rating per item, namely the one which corresponds best to the common parlance of native German speakers.

\section{Results}

Corrected item-total correlations and exploratory factor analysis

Corrected item-to-total correlations (CITCs) ranged from .26 to .76, and the median of all corrected item-total correlations was .53. Different cut-off values for inclusion or deletion of items are reported in the literature. For example, Bearden, Hardesty and Rose (2001) used a decision rule of CITCs greater than .35 to retain items. Netemeyer, Bearden, and Sharma (2003) recommended CITCs in the $.50-.80$ range for retention. 
Six of the ABET items did not meet the .35 criterion; eight had a CITC below .50. But only two, namely ABET 6 and ABET 30, did not have a CITC higher than the item-total correlation (ITC), a relative criterion which is more meaningful than any absolute cutoff value.

A first principal components analysis using oblimin rotation was computed for the 30 ABET items. Results not only supported the a priori assumption that the ABET would assess five different types of sensitivities to the beautiful and the good, but also confirmed what the corrected item-to-total correlations had already indicated: all items of the three artistic and of the two non-aesthetic goodness subscales loaded on separate factors, except for ABET6 and ABET 30. Table 1 presents the results of a second oblimin rotated principal component analysis which was carried out after deletion of these two items.

Insert Table 1 about here

As can be seen from Table 1, two items had double-loadings (differences $<.05$ ), and the total variance explained by the five factors was 53.91. Correlations between the components ranged from -.27 (music and moral factors) to .24 (lyric and moral factors). Descriptive statistics and scale intercorrelations

In a next step, mean scores, standard deviations, skewness and kurtosis, as well as reliabilities were computed for all ABET subscales and for the ABET total score (see Table 2).

Insert Table 2 about here 
Table 2 shows that skewness and kurtosis indicated normal distribution of all scales, except for ABET Talent, which was peaked $(K>1.96)$. Standard deviations ranged from .61 (ABET Total) to 1.00 (ABET Moral). The ABET scales yielded sufficient to high internal consistencies, with alphas between.65 (ABET Talent) to .88 (ABET Art and ABET Total). Subscale means went from 2.26 (ABET Moral) to 3.91 (ABET Talent). Participants seemed to experience beauty or excellence mostly when listening to music, looking at paintings, or viewing the talent-excellence of another person, and less so when listening to poems or reading about moral goodness. The mean of ABET Total (3.04) was slightly above the midpoint of the scale (2.5). Correlations with demographics were generally small in size; only the correlation between age and appreciation of paintings (.16) was statistically significant. The scale inter-correlations went from .07 (appreciation of skills and talents with appreciation of lyric) to .50 (appreciation of music with appreciation of paintings).

\section{Discussion}

The main result of this first study was that the responsiveness to different types of goodness, could be differentiated, which suggests that appreciation is not unidimensional, but consists of different sensitivities which may be grouped together on a higher level. This result is of interest, because it supports the main assumption of both the appreciation and the engagement model. Furthermore, it confirms the findings of Diessner et al. (2008), who showed that the three subscales of their EBS resolved, in a principal component analysis, into distinct factors, but reported correlations between these factors ranging from .48 to .68 .

In this sample, the reliabilities of the ABET subscales were satisfying. . Two items did not meet the criterion of the CITC being lower than the ITCs and did not load on their respective factors. The first, ABET6, was an excerpt of modern, nearly 
experimental Swiss folk music, which went with ABET Lyric and loaded on the lyric factor, indicating that this type of music is less related to the intuitive, emotional experience typical for classical, jazz and pop music than to the more intellectual, abstract appreciation of poetry. The second, ABET30 was a video clip showing the astounding skills of a virtuoso violinist. The fact that the skills he displayed were related to music probably lead to correlations with appreciation of music: a person watching this video-clip might focus on its "music aspect", instead of its "skills aspect". We decided to delete these two items for all subsequent analyses, in order to find an optimal balance between both content validity (i.e. presenting the participants with as different examples as possible) and homogeneity of the scales.

\section{Study 2: Structure of Appreciation}

The main aim of study 2 was to examine the models proposed by Haidt and Keltner (2004), and Diessner et al. (2008) using structural equation modeling. Additionally, we planned to confirm and further refine the findings of the first study with a larger and more heterogeneous sample. Finally, we intended to correlate the ABET with two existing measures of appreciation, the EBS (Diessner et al., 2008) and the ABE subscale of the VIA-IS (Peterson \& Seligman, 2005) to examine the relationships between these self-ratings measures and the newly created test (concurrent validity). We expected medium to high positive correlations between the EBS and the ABE subscale, and predicted lower but still significant correlations between these two self-report instruments and the ABET, which is a stimulus-based test.

\section{Methods}

\section{Participants}

The sample consisted of 439 German-speaking adult volunteers (276 women, 163 men) aged 18 to 86 years $(\mathrm{M}=42.21 ; \mathrm{SD}=12.90)$. With respect to their highest educational 
achievement, $5 \%$ of the participants indicated to have achieved compulsory education, $38 \%$ an apprenticeship, $12 \%$ a baccalaureate, and $45 \%$ a University degree; $58 \%$ indicated being married or living with their partner, $42 \%$ lived alone (single, divorced, or widowed). In regard to employment, $75 \%$ reported to be working, and $25 \%$ to be presently unemployed, studying, or retired.

Instruments

Participants completed the ABET; following the analyses conducted in study 1, only 28 items were retained for this second study, and only one "beauty" or "excellence" score per item was taken into account. In this sample, reliabilities ranged from .69 (ABET Talent) to .88 (ABET Art and Total).

The Values in Action Inventory of Strengths (VIA-IS; Peterson, Park, \& Seligman, 2005) consists of 240 items for the self-assessment of the 24 character strengths (10 items per strength) included in the classification of Peterson and Seligman (2004). Participants filled in the whole questionnaire, but only the ABE subscale, which is concerned with both aesthetic and non-aesthetic goodness, and consists of items alluding to physical beauty (art and surroundings), as well as virtue or moral goodness, was considered within the scope of the study. The VIA-IS uses a 5-point rating format (from very much like me to very much unlike me). A sample item is: "I experience deep emotions when I see beautiful things" (ABE). The German adaptation of the VIA-IS (Ruch et al., 2010) was already validated in a variety of contexts (e.g. Güsewell \& Ruch, 2012; Harzer \& Ruch, in press a, b; Müller \& Ruch, 2011). Ruch et al. (2010) reported an internal consistency of .73 for the ABE subscale which, in our sample, had an alpha of .72 .

The Engagement with Beauty Scale (EBS; Diessner et al., 2008) is the first standalone instrument concerned with the sensitivity to different types of the beautiful 
and the good. It consists of 14 items for the self-assessment of Engagement with Natural Beauty (4 items), Engagement with Artistic Beauty (4 items) and Engagement with Moral Beauty (6 items). The EBS offers a total score and scores for each of the three subscales. It uses a 5-point rating format ranging from very much unlike me to very much like me. A sample item is "When perceiving beauty in nature I feel changes in my body, such as a lump in my throat, an expansion in my chest, faster heartbeat, or other bodily responses" (Natural Beauty). Diessner et al. (2008) report a Cronbach $\alpha$ of .90 for the total score and alphas ranging from .80 to .87 for the subscales. In this study we used the German version by Dachs and Diessner (2009), which was tested with a sample of N = 69 participants. According to Dachs and Diessner (2009), they could reproduce the initial factor structure in the German version, and reliabilities ranged from .94 (EBS total score) to .85 (Natural Beauty and Artistic Beauty subscales). In our sample, reliabilities went from .71 (Natural), to .81 (Artistic and Moral), with $\alpha=.85$ for the Total score.

\section{Procedure}

Participants took the ABET, the whole VIA-IS and the EBS on a website which was created specifically for the purpose of this research in spring 2010. The study was promoted by means of short newspaper and magazine contributions, by flyers and posters, and by contacting directly specific population groups (e.g. retired persons, young mothers with children, different cultural and athletic societies) in order to get a heterogeneous sample. Respondents registered on the website from their own personal computers; they were not paid for participating, but took part in a raffle and received standardized feedback about their character strengths profile. Only participants who had completed the whole survey ( $67 \%$ of the $\mathrm{N}=655$ who started filling it in) were included 
in the sample ${ }^{1}$. As the online survey did not allow skipping any questions, the data set contained no missing data.

Data analysis

A structural equation modeling analysis using SPSS Amos (Version 18; Arbuckle, 2007) was carried out to examine the structure of appreciation. All models included in this analysis met the following theoretical assumptions: (a) appreciation (or engagement) is a general sensitivity for goodness in the physical and social worlds; (b) appreciation (or engagement) is multi-dimensional, and encompasses at least two dimensions, aesthetic and non-aestethic goodness, but might possibly comprise three dimensions; (c) these two or three dimensions are related, but distinct. Additionally, all models were tested with a method factor representing the systematic variance introduced by the new type of measurement instrument developed (i.e. stimulus-based test instead of self-report questionnaire): the $\mathrm{ABE}$ and the EBS require participants to give a reflected assessment of their reactions to beauty and goodness, whereas the ABET asks for a spontaneous assessment of their actual reactions to different types of stimuli.

The following three models were tested: (1) two-dimensional appreciation model, a two-dimensional variant of Haidt and Keltner's (2004) model, comprising the sensitivity for goodness in the physical world on the one hand, and the sensitivity for goodness in the social world on the other hand; (2) three-dimensional appreciation model, corresponding to the three dimensions hypothesized by Haidt and Keltner (2004), namely physical beauty, skill or talent, and virtue or moral goodness; (3)

\footnotetext{
${ }^{1}$ The $\mathrm{N}=216$ participants who did not complete the survey were on average slightly older $(\mathrm{M}=44.80)$ than those who did $(\mathrm{M}=42.21)$. Furthermore, the proportion of men was lower in this group $(13.9 \% \mathrm{vs} .27 .1 \%)$. With respect to employment, comparison between the two sub-groups is impossible, as most of those who dropped out did not come across the socio-demographic questions.
} 
engagement model, encompassing the three dimensions Diessner et al.(2008) included in their model, that is natural, artistic, and moral beauty.

The ABE subscale of the VIA-IS comprises no subscales. Nonetheless, its ten items address different types of goodness and can therefore be grouped content wise. Haidt and Keltner (2001) discussed the fact that an ideal self-report instrument assessing the emotional responsiveness to various kinds of beauty and excellence "should specify the various potential sub-types of beauty and excellence, and then offer several potential items within each subtype" (p. 10). They proposed a list of such sub-types, together with 22 corresponding items, eight of which were actually included in the VIA, together with two additional ones. Following Haidt and Keltner's (2001) tentative classification, these ten items relate to appreciation of one's surroundings, appreciation of art, and appreciation of non-aesthetic goodness. An exploratory oblimin rotated principal component analysis on item level yielded a three-factor solution which came close to Haidt and Keltner's (2001) a-priori classification and suggested to create the following three clusters for the purpose of the structural equation modeling analysis: $\mathrm{ABE}$ Environment (ABE 89, 137, 185; $\alpha=.62)$, ABE Art (ABE 161, 209, 233; $\alpha=.71)$, and ABE Awe (ABE 17, 41, 65, 113; $\alpha=.65)$.

The fit of the three alternative models was tested using the p-value of the chisquare ( $\chi^{2}$; Hair, Anderson, Tatham, \& Black, 2006), the goodness-of-fit index (GFI), the adjusted goodness-of-fit index (AGFI), and the root-mean-square error of approximation (RMSEA; Hu \& Bentler, 1998) as criteria. A non-significant p-value of chi-square $\left(\chi^{2}\right)$ indicates a good fit. As the chi-square statistic is very sensitive to sample size (Hair et. al., 2006), a significant value is to be expected for large sample sizes. Therefore, additional indices should always be taken into account when evaluating the fit of a model (Bentler, 1990; Hu \& Bentler, 1999). Widely used alternatives include the 
goodness-of-fit index (GFI), the adjusted goodness-of-fit index (AGFI), and the rootmean-square error of approximation (RMSEA). A GFI and an AGFI higher or equal .90 indicate a good-fitting model, a GFI and an AGFI higher or equal .95 an excellentfitting model. For the RMSEA, values equal to or lower than .08 can be interpreted as an acceptable fit.

\section{Results}

Preliminary analyses

In this sample, skewness and kurtosis indicated normal distribution of all scales.

Correlations with demographics were small in size, yet statistically significant in some cases, due to the number of participants. Women scored higher on the $\mathrm{ABE}(r=.13)$ than men, showed greater sensitivity to music and examples of virtue and moral goodness (ABET Music, $r=.13$; ABET Moral, $r=.11$ ), and greater engagement with natural and moral beauty (EBS Natural, $r=.19$; EBS Moral, $r=.17$ ). Age was related positively to appreciation of paintings and of lyric (ABET Painting, $r=.16$; ABET Lyric, $r=.10$ ), and to engagement with artistic beauty (EBS Art, $r=.16$ ). Therefore, all subsequent correlational analyses controlled for a potential impact of these demographic variables.

Scale inter-correlations and concurrent validity

Correlations among the ABET, EBS, and ABE subscales are shown in Table 3.

Insert Table 3 about here

With respect to the scale intercorrelations, three questions were of interest. First, whether scales concerning similar contents would show higher correlations among each other, than with other scales. Results showed that Engagement with artistic beauty (EBS Artistic) had its highest correlation with appreciation of art (ABET Art), and that 
engagement with moral beauty (EBS Moral) had its highest correlation with appreciation of virtue and moral goodness (ABET Moral). Likewise, the three VIA clusters had their highest correlations with the three corresponding EBS subscales (.49 to .51$)$. It can therefore be assumed that related subscales actually measure related constructs. The second question we intended to examine, was whether the influence of the two methods would become apparent, that is whether the scale-intercorrelations would be higher within the methods, than between. And indeed, the correlations of the ABET scales with EBS Total and ABE were numerically lower than the correlations of the EBS scales with ABE, as expected (test versus self-report questionnaires). And finally, we wanted to see how appreciation of beauty and excellence as measured with the ABE subscale of the VIA-IS would be correlated with each of the three ABET subscales. Table 3 shows that ABE mainly went together with appreciation of physical beauty (ABET Art), to a lesser extent with appreciation of moral goodness (ABET Moral), and hardly with appreciation of skills and talents (ABET Talent).

\section{Correlations to relevant socio-demographic variables}

Correlations with five "appreciation-relevant" behaviors in everyday life were computed (convergent validity). It was expected that participants in an artistic profession (e.g. musician, painter, and architect) would display a significantly higher sensitivity to artistic goodness than other participants, which was partly confirmed (Bonferroni corrected significant correlations with $\mathrm{ABE}$ and EBS Artistic, but not with ABET Art).

Furthermore, it was hypothesized that the responsiveness to artistic goodness would correlate positively with the frequency of concert attendance, and the data supported this assumption (Bonferroni corrected significant correlations with ABET Art and EBS Artistic). Interestingly, higher scores on overall measures of the sensitivity to the beautiful were also were positively related to the frequency of concert attendance 
(Bonferroni corrected significant correlations with ABE and ABET Total), as if this type of leisure activity was not only linked to a specific sensitivity for beauty in the physical world, but also to a more general sensitivity to beauty and excellence.

Furthermore, we had expected that persons indicating that sport was their main leisure activity would be particularly sensitive to skills and talents (ABET Talent); that participants mentioning reading and literature as their favorite hobby would be especially responsive to the beauty of poems (ABET Lyric); and that those who spend most of their free time with family and friends would be highly responsive to goodness in the social world (ABET Moral or EBS Moral). However, these hypotheses were not confirmed.

Structure of Appreciation of Beauty and Excellence

Initial covariances of all subscales are displayed in Table 3 (Mueller \& Hancock, 2008, p. 505). In a first step, each of the three models discussed in the method section was examined (Table 4).

Insert Table 4 about here

Table 4 shows that the appreciation model converged only without second order factor. However, as even this variant yielded an insufficient fit, the two-dimensional model was not considered any further. The three-dimensional appreciation model failed to converge, with and without second-order factor. Therefore, no fit indices are provided for this model. The comparatively best fit was observed for the engagement model.

The EBS and the ABE are both self-report questionnaires However, there is a major difference between these two instruments: whereas the EBS addresses actual emotions (i.e. a sense of awe, or wonder or excitement or admiration or upliftment), bodily feelings (i.e. a lump in one's throat, an expansion in one's chest, faster heart 
beat), or spiritual experiences (i.e. a sense of oneness, or being united with the universe, or a love of the entire world) related to the perception of beauty, the $\mathrm{ABE}$ is rather concerned with thoughts and cognitions (e.g. I'm always aware of, it's important to me, I see). The specific, emotional and bodily component of the EBS could have an impact on the rating-behavior of participants, and consequently, the residuals belonging to its three subscales might co-vary in a specific way. To examine this hypothesis, we allowed the error terms to correlate and run the model again. Following the introduction of the covariances, all fit indices improved. As the difference between the Chi square values was highly significant, this model was finally retained (see Figure 2).

Insert Figure 2 about here

Preliminary analyses had shown significant correlations of some of the subscales with socio-demographic variables, mainly sex; therefore, the final model was computed separately for men and women. The table of critical ratios of differences among all pairs of free parameters was examined, and showed that men and women differed significantly only with respect to one single parameter, namely the loading of "ABE Moral" on "test", which was higher for women (.38) than for men (.06). Thus, future model testing should consider testing for invariance across gender. Nevertheless, the structural model was valid for both gender groups, and hence Figure 2 presents the results for the combined sample.

\section{Discussion}

The results of the structural equation modeling analysis confirmed the basic assumptions of both Haidt and Keltner (2004) and Diessner et al. (2008), namely that appreciation or engagement is a general sensitivity to the beautiful and the good, which encompasses distinct, but related dimensions. The three-dimensional model which 
demonstrated the best fit in this study distinguished between the sensitivity for beauty in nature and surroundings, the sensitivity for artistic beauty, and the sensitivity for nonaesthetic goodness. At first glance, this structure corresponds to the three dimensions suggested by Diessner et al. (2008). On closer inspection, there is one notable difference between their engagement model and our resulting model, namely the fact that skills and talents are included, and that they cluster together with the sensitivity for moral goodness. This in turn supports Peterson and Seligman's idea of a specific sensitivity to the goodness in social world. Actually, our resulting model - although resembling the engagement model - is a combination of the engagement and the appreciation model. We chose to label it responsiveness to the good and beautiful model. The term "responsiveness" reflects the fact that both appreciation of and engagement with beauty go beyond the simple perception or awareness of the existence of beauty: they are conceived as reactions to beauty, appreciation as a cognitive reaction and engagement as an emotional reaction.

In terms of convergent validity, the $\mathrm{ABET}$, the $\mathrm{ABE}$ and the EBS showed substantial positive correlations. The correlations of the ABET with the ABE and the EBS proved to be lower than the correlations between ABE and EBS, as was expected due to method variance, but still high enough to show that the two self-report questionnaires and the objective test seemed to measure the same characteristic. Diessner et al. (2008) wrote that "the overall high correlation between the ABE and the EBS shows that they are similar enough to be used as alternate forms in future research" (p. 311). The ABET is not an alternative to the two existing questionnaires, but supplemental: it contributes to the understanding of the construct of appreciation by adding evidence from a different perspective. Both types of assessment (i.e. self-report questionnaire and test) yield results that fit the expected nomological net. The fact that 
musicians and other artists displayed a higher sensitivity to artistic goodness than other participants, and that the overall responsiveness to beauty and excellence correlated positively with the frequency of concert attendance adds important information. Further validation studies that substantiate the relations to other concepts and validity information are needed.

\section{General Discussion}

This research tentatively adds a new three-factor model of the sensitivity to the beautiful and the good to the two already existing ones, or rather shows that these two models can be integrated into a broader one. Our resulting model, which was labeled responsiveness to the good and beautiful, is not intended as a definitive one but should rather be considered as a first proposal and an invitation to ongoing research and debate.

The fact that appreciation of beauty and excellence and engagement with beauty could be combined in a broader model suggests these two constructs are closely related. The difference between appreciation and engagement mainly lies in the degree of emotional involvement of the observer. Whereas Haidt and Keltner (2004) assume that beauty elicits awe and awe-related emotions "in the strongest cases" (p. 537), Diessner et al. (2008) posit that there is no engagement without deep emotional involvement of the observer. This means that appreciation without engagement is conceivable, but engagement without appreciation is not. We therefore conceive responsiveness to the good and beautiful as a continuum, stretching from cognitive appreciation to deep engagement, with all imaginable intermediate degrees of emotional involvement.

Haidt and Keltner (2004) raised the question, "are there multiple channels by which to connect with beauty and excellence[?]" (p. 538). Our findings definitively give an answer to this question: responsiveness to the good and the beautiful is a general sensitivity to the beautiful and the good, which encompasses distinct, but related 
dimensions. Within the overall frame of responsiveness, different combinations of these more specific dimensions do exist. Some individuals may be particularly sensitive to beauty of music, and less to other types of artistic beauty; others may have a strong sensitivity to moral excellence, and natural beauty, but not at all to human-made objects of art. The fact, that responsiveness is multi-dimensional raises the question, whether typical "responsiveness-profiles" can be ascertained for specific professions. For example, musicians, athletes, or priests might show a specific responsiveness to one or several types of goodness. In fact, our results point in this direction: persons indicating they have an artistic profession displayed higher levels of sensitivity to artistic beauty than other participants. Further research on this topic is needed.

Each of the three instruments included in this research assessed the sensitivity to some of the different types of beauty and goodness comprised in Haidt and Keltner's (2004) and Diessner et al.'s (2008) models, but none assessed them all. Whereas the sensitivity to virtue and moral goodness was measured by all three instruments, only the ABET was concerned with the sensitivity to skills and talents, and only self-report questionnaires (ABE and $\mathrm{EBS}$ ) with the sensitivity to nature and surroundings. It will therefore be necessary to conceive one single instrument, taking into account all types of goodness, in order to check if the findings of this research can be confirmed. A fruitful next step will be the development of an even more comprehensive instrument measuring responsiveness to the good and beautiful. This instrument will include other areas of beauty and goodness (such as the beauty of human bodies or of abstract patterns in nature), and would incorporate these aspects into the existing three dimensions.

The ABET, which was created for the purpose of this research, showed good reliability, as well as convergent validity, and can therefore be recommended for further research. Nevertheless, some limitations of this instrument need to be mentioned. 
Firstly, the stimuli of the ABET are linked to the cultural context in which the research took place. Art, but also ideas about what is excellent may always be bound to a culture, a society, a religious, philosophical and historical background. Therefore, the ABET aims not at being a culture-free, or cross-cultural appreciation test. Secondly, in order to keep the length of the ABET within a reasonable range, we had to reduce on the number of items in pre-studies. We tried to present the participants with an item-pool as diverse as possible, but cannot exclude that somebody's musical, or literary, or pictorial preferences were not addressed. Thirdly, the question is, whether an emotional response to beauty or excellence can be elicited several times in straight succession. If the task is not too unusual for pictures - the visitor of a painting exhibition usually contemplates even more numerous paintings - it is a difficult one for a series of short stories describing acts of moral goodness. The first story will probably elicit a strong emotional reaction, but the following could have less impact. And finally, if an online-survey is perfect for any type of artistic beauty items, it is less suitable for items relating to the beauty of nature, skills or talents, and moral goodness. Therefore, one challenge for future research might be to conceive study designs which create more "real-life" conditions, specifically with respect to nature, which is missing in the ABET.

Another limitation of our research is related to the fact that the whole survey took about one hour and a half to be filled in. It may therefore be assumed that only participants really interested in the topic and somewhat sensitive to beauty and excellence went on until the very end (i.e. self-selection of the participants). Furthermore, although we tried to make our survey as user-friendly as possible, some interested participants may have given up because they were faced with technical challenges they could not overcome. Therefore, although our sample was well balanced with respect to age, education, and occupational status, it is possible that it was non- 
representative with respect to other characteristics, and that this difference could have influenced the results.

Our research showed that participants' ratings of the beauty or excellence items not only depended on their sensitivity to artistic beauty, to the display of outstanding skills and talents, or to moral beauty, but also on the very specific contents each of these three sensitivities applied to. This idea is borrowed from Jaeger's (1984) model of intelligence, which crosses four operations with three classes of contents on which these operations apply. Our research highlights how difficult it is to separate a specific sensitivity from the content on which it applies. In the ABET Talent scale, participants gave different ratings to excellence in artistic or athletic domains compared to intellectual or moral domains. Whereas the former elicited both the experience of beauty and excellence, the latter elicited only the experience of excellence. There is no "absolute" or "content-free" appreciation of outstanding skills or talents, and the sensitivity to distinct types of skills and talents (e.g. intellectual, athletic, musical) may well be differently pronounced in one person. One possible way to overcome the abovementioned difficulty could be a more directive test-instruction, telling the participants on which aspect of the items to focus: either the excellence aspect, or the auditory or visual beauty aspect, or even both, but in a separate rating.

As an alternative, a closer look at the relations between different types of excellence and the emotions they elicit might allow a better understanding of possible distinctions between different types of goodness in the social world. Haidt and Keltner (2004) view appreciation as "[...] emotional responsiveness, the tendency to experience at least subtle self-transcendent emotions" (p. 538), and assume that different kinds of goodness produce "distinct awe-related emotions" (p. 538) in observers: beauty elicits 
awe, skill elicits admiration, and virtue elicits the emotion of moral elevation. Diessner (personal communication, July 16, 2010) agrees with this idea, when he writes:

Based on Haidt's work, the main difference between moral beauty and moral excellence, AND non-moral excellence (skills \& talents) would be that moral beauty/ excellence arouses elevation (and thus a desire to be a better person and help others), and that non-moral excellence (skills/talents) arouses admiration (with no concomitant desire to become a better person or help others). Algoe and Haidt (2009) studied the other praising family of emotions, a group of emotions which arise from other's exemplary actions (i.e. gratitude, admiration, and elevation. They showed that each of these emotions not only had specific elicitors, but was also accompanied by typical physical sensations, and lead to unique motivational, or relationship consequences. These findings suggest that further research on responsiveness to the good and beautiful, might benefit from a focus on physical sensations, motivations, and relationship consequences, additionally to self-reports, or ratings of beauty and excellence experienced. 


\section{Tables}

Table 1. Oblimin five-factor rotated solution for the ABET (principal component analysis).

Table 2. Descriptive statistics, reliabilities, correlations with age and sex, and intercorrelations of the ABET scales.

Table 3. Correlations and covariances of the ABET, EBS, and ABE subscales. Table 4. Fit of the different structural models.

\section{Figures}

Figure 1. Structural Models: a) Appreciation of Beauty and Excellence (Haidt \& Keltner, 2004), and b) Engagement with Beauty (Diessner et al., 2008).

Figure 2. Final three-dimensional structural equation model of responsiveness, standardized solution. 


\section{References}

Algoe, S. B., \& Haidt, J. (2009). Witnessing excellence in action: the 'other-praising' emotions of elevation, gratitude, and admiration. The Journal of Positive Psychology, 4, 105-127. doi:10.1080/17439760802650519

Arbuckle, J. L. (2007). Amos тм18 user's guide. Crawfordville, FL: Amos Development Corporation.

Bentler, P. M. (1990). Comparative fit-indexes in structural models. Psychological Bulletin, 107, 238-246. doi:10.1037/0033-2909.107.2.238

Costa, P. T., \& McCrae, R. R. (1992). The revised NEO personality inventory (NEO-PI$R$ ) and NEO five factor inventory (NEO-FFI) professional manual. Odessa, FL: Psychological Assessment Resources.

Dachs, I., \& Diessner, R. (2009). German Version of the Engagement with Beauty Scale. Psi Chi - Journal of Undergraduate Research, 14(3), 87-92. https://www.psichi.org/Pubs/Articles/Article_785.aspx

Diessner, R., Rust, T., Solom, R.C., Frost, N., \& Parsons, L. (2006). Beauty and hope: A moral beauty intervention. Journal of Moral Education, 35, 301-317. doi:10.1080/03057240600874430

Diessner, R., Solom, R., Frost, N.K., Parsons, L., \& Davidson, J. (2008). Engagement with beauty: appreciating natural, artistic, and moral beauty. The Journal of Psychology: Interdisciplinary and Applied, 142, 303-329. doi:10.3200/JRLP.142.3.303-332

Eid, M., Lischetzke, T., \& Nussbeck, F. W. (2006). Structural equation models for multitrait-multimethod data. In M. Eid \& E. Diener (Eds). Handbook of 
multimethod measurement in psychology (pp. 283-299). Washington, DC: American Psychological Association. doi:10.1037/11383-020

Emerson, R. W. (1941). Essays of Ralph Waldo Emerson. Including essays, first and second series, English traits, nature and conduct of life. New York, NY: The Book League of America.

Güsewell, A., \& Ruch, W. (2012). Are only emotional strengths emotional? Character strengths and disposition to positive emotions. Applied Psychology: Health and Well-Being, 4, 218-239. doi:10.1111/j.1758-0854.2012.01070.x

Haidt, J. \& Keltner, D. (2001). Chapter 3.21. Awe/Responsiveness to Beauty and Excellence (Initial draft by Jonathan Haidt \& Dacher Keltner). In C. Peterson \& M. E. P: Seligman (eds.), The Values in Action (VIA) classification of strengths. Cincinnati, OH: Values in Action Institute.

Haidt, J., \& Keltner, D. (2004). Appreciation of beauty and excellence [awe, wonder, elevation]. In C. Peterson \& M. E. P. Seligman (Eds.). Character strengths and virtues (pp. 537-551). New York, NY: Oxford University Press.

Hair, J. F., Anderson, R. E., Tatham, R. L., \& Black, W. (2006). Multivariate data analysis. Upper Saddle River, NJ: Prentice Hall.

Harzer, C., \& Ruch, W. (in press a). The application of signature character strengths and positive experiences at work. Journal of Happiness Studies. doi:10.1007/s10902-012-9364-0

Harzer, C., \& Ruch, W. (in press b). When the job is a calling: The role of applying one's signature strengths at work. The Journal of Positive Psychology. doi:10.1080/17439760.2012.702784 
Hu, L., \& Bentler, P. M. (1998). Fit indices in covariance structure modeling: Sensitivity to underparametrized model misspecification. Psychological Methods, 3, 424-453. doi:10.1037/1082-989X.3.4.424

Hu, L., \& Bentler, P. M. (1999). Cutoff criteria for fit indexes in covariance structure analysis: Conventional criteria versus new alternatives. Structural Equation Modeling, 6, 1-55. 10.1080/10705519909540118

Jäger, A. O. (1984). Intelligenzstrukturforschung: Konkurrierende Modelle, neue Entwicklungen, Perspektiven [Research on the structure of intelligence: Competing models, new developments, perspectives]. Psychologische Rundschau, 35, 21- 35 .

Maslow, A. (1964). Religions, values, and peak experiences. New York, NY: Penguin. Mueller, R. O., \& Hancock, G. R. (2008). Best practices in structural equation modeling. In J. W. Osborne (Ed.), Best practices in quantitative methods (pp. 488-508). Thousand Oaks, CA: Sage Publications, Inc.

Müller, L., \& Ruch, W. (2011). Humor and strengths of character. The Journal of Positive Psychology, 6, 368-376. doi:10.1080/17439760.2011.592508

Netemeyer, R. G., Bearden, W. O., \& Sharma, S. (2003). Scaling procedures: Issues and applications. Thousand Oaks, CA: Sage.

Peterson, C., Park, N., \& Seligman, M. E. P. (2005). Assessment of character strengths. In G. P. Koocher, J. C. Norcross, \& S. S. Hill III (Eds.), Psychologists’ desk reference (Vol. 3, pp. 93-98). New York, NY: Oxford University Press.

Peterson, C., \& Seligman, M. E. P. (2004). Character strengths and virtues. New York, NY: Oxford University Press. 
Ruch, W., Proyer, R. T., Harzer, C., Park, N., Peterson, C., \& Seligman, M. E. P. (2010). Values in action inventory of strengths (VIA-IS). Journal of Individual Differences, 31, 138-149. doi:10.1027/1614-0001/a000022 
Table 1. Oblimin five-factor rotated solution for the ABET (principal component analysis).

\begin{tabular}{|c|c|c|c|c|c|c|}
\hline \multirow{4}{*}{$\begin{array}{l}\text { eigenvalue } \\
\text { variance explained }\end{array}$} & \multicolumn{5}{|c|}{ factors } & \multirow[b]{4}{*}{$h^{2}$} \\
\hline & painting & moral & talent & lyric & music & \\
\hline & 7.00 & 2.84 & 2.56 & 1.46 & 1.24 & \\
\hline & 24.98 & 10.15 & 9.14 & 5.22 & 4.42 & \\
\hline \multicolumn{7}{|l|}{ ABET Music } \\
\hline 3 & .23 & .11 & .12 & .33 & -.73 & .60 \\
\hline 13 & .25 & .18 & .25 & .13 & -.63 & .42 \\
\hline 16 & .40 & .21 & .39 & .15 & -.60 & .48 \\
\hline 21 & .55 & .20 & .30 & .31 & -.63 & .60 \\
\hline 26 & .16 & .21 & .39 & -.19 & -.36 & .30 \\
\hline \multicolumn{7}{|l|}{ ABET Painting } \\
\hline 2 & .38 & .17 & -.04 & .09 & -.39 & .27 \\
\hline 9 & .63 & .15 & .04 & .02 & -.41 & .49 \\
\hline 12 & .71 & .06 & .14 & .07 & -.38 & .55 \\
\hline 18 & .79 & .16 & .21 & .29 & -.33 & .66 \\
\hline 23 & .74 & .18 & .12 & .47 & -.11 & .66 \\
\hline 29 & .81 & .17 & .27 & .25 & -.10 & .71 \\
\hline \multicolumn{7}{|l|}{ ABET Lyric } \\
\hline 5 & .18 & .27 & .08 & .74 & -.29 & .60 \\
\hline 8 & .14 & .20 & -.18 & .76 & -.07 & .60 \\
\hline 11 & .19 & .22 & .10 & .77 & -.12 & .61 \\
\hline 19 & .53 & .37 & .17 & .67 & -.30 & .65 \\
\hline 24 & .54 & .31 & .06 & .60 & -.39 & .59 \\
\hline 28 & .44 & .43 & -.07 & .57 & -.10 & .52 \\
\hline \multicolumn{7}{|l|}{ ABET Talent } \\
\hline 1 & .06 & .09 & .40 & -.01 & -.33 & .22 \\
\hline 10 & .01 & .10 & .59 & .08 & -.14 & .37 \\
\hline 15 & .09 & .14 & .67 & -.07 & -.19 & .46 \\
\hline 22 & .21 & .23 & .68 & -.03 & -.08 & .50 \\
\hline 27 & .22 & .07 & .73 & -.02 & -.19 & .55 \\
\hline \multicolumn{7}{|l|}{ ABET Moral } \\
\hline 4 & -.07 & .63 & -.05 & .18 & -.12 & .46 \\
\hline 7 & -.04 & .61 & .26 & .15 & -.39 & .51 \\
\hline 14 & .11 & .80 & .05 & .23 & .00 & .66 \\
\hline 17 & .22 & .78 & .25 & .13 & -.06 & .65 \\
\hline 20 & .23 & .79 & .16 & .24 & -.20 & .64 \\
\hline 25 & .20 & .86 & .20 & .23 & -.17 & .75 \\
\hline
\end{tabular}

Note. $\mathrm{N}=246$. Bold indicates the highest factor loadings of the scales. 
Table 2. Descriptive statistics, reliabilities, correlations with age and sex, and intercorrelations of the ABET scales.

\begin{tabular}{|c|c|c|c|c|c|c|c|c|c|c|c|c|c|}
\hline & \multicolumn{4}{|c|}{ Descriptive statistics } & \multirow{2}{*}{$\frac{\text { Reliability }}{\alpha}$} & \multicolumn{2}{|c|}{ Demographics } & \multicolumn{6}{|c|}{ Scale intercorrelations } \\
\hline & $M$ & $S D$ & $S$ & $K$ & & Age & Sex & Music & Painting & Lyric & Art & Talent & Moral \\
\hline \multicolumn{14}{|l|}{ ABET } \\
\hline Music & 3.77 & .81 & -.87 & 1.14 & .71 & .00 & .09 & & & & & & \\
\hline Painting & 3.22 & .92 & -.24 & -.56 & .81 & $.16^{*}$ & -.07 & $.50 * * *$ & & & & & \\
\hline Lyric & 2.31 & .92 & .37 & -.54 & .83 & .06 & -.05 & $.41 * * *$ & $.49 * * *$ & & & & \\
\hline Art & 3.06 & .71 & -.20 & -.38 & .88 & .10 & -.02 & $.75^{\mathrm{a}}$ & $.84^{\mathrm{a}}$ & $.81^{\mathrm{a}}$ & & & \\
\hline Talent & 3.91 & .75 & -1.26 & 2.13 & .65 & .07 & .04 & $.38 * * *$ & $.25 * * *$ & .07 & $.28 * * *$ & & \\
\hline Moral & 2.26 & 1.00 & .52 & -.66 & .85 & -.02 & -.02 & $.27 * * *$ & $.22 * * *$ & $.41 * * *$ & $.38 * * *$ & $.23 * * *$ & \\
\hline Total & 3.04 & .61 & -.19 & -.15 & .88 & .08 & -.01 & $.72^{\mathrm{a}}$ & $.74^{\mathrm{a}}$ & $.74^{\mathrm{a}}$ & $.91^{\mathrm{a}}$ & $.50^{\mathrm{a}}$ & $.67^{\mathrm{a}}$ \\
\hline
\end{tabular}

Note. $\mathrm{N}=246(\mathrm{men}=74$, women $=172) . S=$ skewness, $K=$ kurtosis, $\alpha=$ Cronbach's $\alpha$, Sex $(1=$ male; $2=$ female $)$.

$* * * p<.001$.

${ }^{\mathrm{a}}=$ correlations of subscales with the corresponding total score are not tested for significance. 
Table 3. Correlations and covariances of the ABET, EBS, and ABE subscales.

\begin{tabular}{|c|c|c|c|c|c|c|c|c|c|c|c|c|}
\hline & ABET & ABET & ABET & ABET & $\mathrm{ABE}$ & $\mathrm{ABE}$ & $\mathrm{ABE}$ & $\mathrm{ABE}$ & EBS & EBS & EBS & EBS \\
\hline & Art & Talent & Moral & Total & Environ & Art & Awe & Total & Natural & Artistic & Moral & Total \\
\hline ABET Art & & .16 & .20 & .35 & .06 & .20 & .06 & .10 & .35 & 1.40 & .75 & 2.50 \\
\hline ABET Talent & $.29 * * *$ & & .12 & .24 & .03 & -.02 & .07 & .03 & .43 & .44 & 1.06 & 1.93 \\
\hline ABET Moral & $.30 * * *$ & $.15^{* *}$ & & .34 & .11 & .08 & .13 & .11 & .65 & .82 & 2.11 & 3.58 \\
\hline ABET Total & $.90^{\mathrm{a}}$ & $.52^{\mathrm{a}}$ & $.61^{\mathrm{a}}$ & & .06 & .14 & .08 & .09 & .43 & 1.11 & 1.09 & 2.63 \\
\hline ABE environ & $.12^{* *}$ & .05 & $.15^{* *}$ & $.16^{* *}$ & & .13 & .19 & .24 & 1.27 & .94 & 1.18 & 3.39 \\
\hline ABE Art & $.39 * * *$ & -.02 & $.12 * * *$ & $.32 * * *$ & $.26 * * *$ & & .09 & .26 & .24 & 1.82 & .81 & 2.87 \\
\hline ABE Awe & $.14 * *$ & $.14 * *$ & $.20 * * *$ & $.21 * * *$ & $.45^{* * *}$ & $.20 * * *$ & & .24 & 1.22 & .98 & 1.92 & 4.12 \\
\hline ABE Total & $.30 * * *$ & .08 & $.21 * * *$ & $.32 * * *$ & $.74^{\mathrm{a}}$ & $.68^{\mathrm{a}}$ & $.77^{\mathrm{a}}$ & & .94 & 1.22 & 1.36 & 3.52 \\
\hline EBS Natural & $.13 * *$ & $.13 * *$ & $.16^{* *}$ & $.18 * * *$ & $.49 * * *$ & $.10^{*}$ & $.50 * * *$ & $.49 * * *$ & & 7.42 & 10.83 & 32.64 \\
\hline EBS Artistic & $.44 * * *$ & $.11^{*}$ & $.18 * * *$ & $.41 * * *$ & $.30 * * *$ & $.51 * * *$ & $.35^{* * * *}$ & $.54 * * *$ & $.42 * * *$ & & 11.26 & 40.05 \\
\hline EBS Moral & $.18 * * *$ & $.21 * * *$ & $.34 * * *$ & $.31 * * *$ & $.28 * * *$ & $.18 * * *$ & $.49 * * *$ & $.44 * * *$ & $.45^{* * *}$ & $.41 * * *$ & & 60.04 \\
\hline EBS Total & $.32 * * *$ & $20 * * *$ & $.31 * * *$ & $.39 * * *$ & $.43 * * *$ & $.34 * * *$ & $.57 * * *$ & $.61 * * *$ & $.74^{\mathrm{a}}$ & $.76^{\mathrm{a}}$ & $.85^{\mathrm{a}}$ & \\
\hline
\end{tabular}

Note. $N=439(\operatorname{men}=163$, women $=276)$. Partial correlations, controlled for age and gender are displayed below, covariances above the diagonal. $* p<.05 . * * p<.01 . * * * p<.001$.

${ }^{\mathrm{a}}=$ correlations of subscales with the corresponding total score are not tested for significance. 
Table 4. Fit of the different structural models.

\begin{tabular}{|c|c|c|c|c|c|c|}
\hline Models & $\chi^{2}(\mathrm{~N}=439)$ & $d f$ & $p$ & RMSEA & GFI & AGFI \\
\hline \multicolumn{7}{|c|}{ 2-dimensional appreciation (Haidt \& Keltner, 2004) } \\
\hline no method factor ${ }^{\mathrm{a}}$ & 312.0 & 26 & $<.001$ & .168 & .85 & .75 \\
\hline with "test" method factor" & 262.9 & 24 & $<.001$ & .151 & .87 & .75 \\
\hline \multicolumn{7}{|c|}{ 3-dimensional appreciation (Haidt \& Keltner, 2004) } \\
\hline no method factor & \multicolumn{6}{|c|}{ model failed to converge } \\
\hline with "test" method factor & \multicolumn{6}{|c|}{ model failed to converge } \\
\hline \multicolumn{7}{|c|}{ 3-dimensional engagement (Diessner et al., 2008) } \\
\hline no method factor (em1) & 165.6 & 24 & $<.001$ & .119 & .92 & .85 \\
\hline with "test" method factor (em2) & 103.1 & 22 & $<.001$ & .094 & .95 & .89 \\
\hline with EBS covariances (em3) & 63.3 & 19 & $<.001$ & .075 & .97 & .92 \\
\hline \multicolumn{7}{|c|}{ Difference between engagement models } \\
\hline$\Delta \chi_{(\mathrm{A})}^{2}=\chi_{(\mathrm{em} 1)}^{2}-\chi_{(\mathrm{em} 2)}^{2}$ & 62.5 & 2 & $<.001$ & & & \\
\hline$\Delta \chi_{(\mathrm{B})}^{2}=\chi_{(\mathrm{em} 2)}^{2}-\chi_{(\mathrm{em} 3)}^{2}$ & 39.8 & 3 & $<.001$ & & & \\
\hline
\end{tabular}

Note. $\mathrm{N}=439$. RMSEA = root-mean-square error of approximation; GFI = goodness-of-fit index; AGFI = adjusted goodness-of-fit index.

${ }^{\mathrm{a}}=$ without second order factor. 
a)

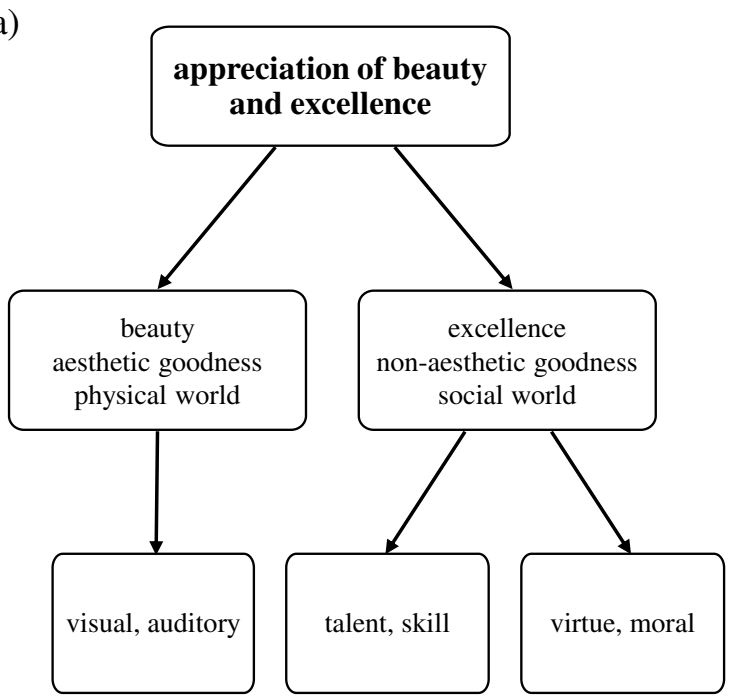

b)

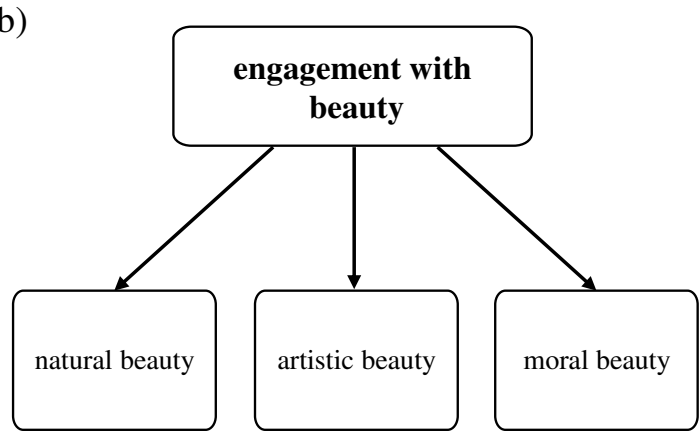

Figure 1. Structural Models: a) Appreciation of Beauty and Excellence (Haidt \&

Keltner, 2004), and b) Engagement with Beauty (Diessner et al., 2008). 


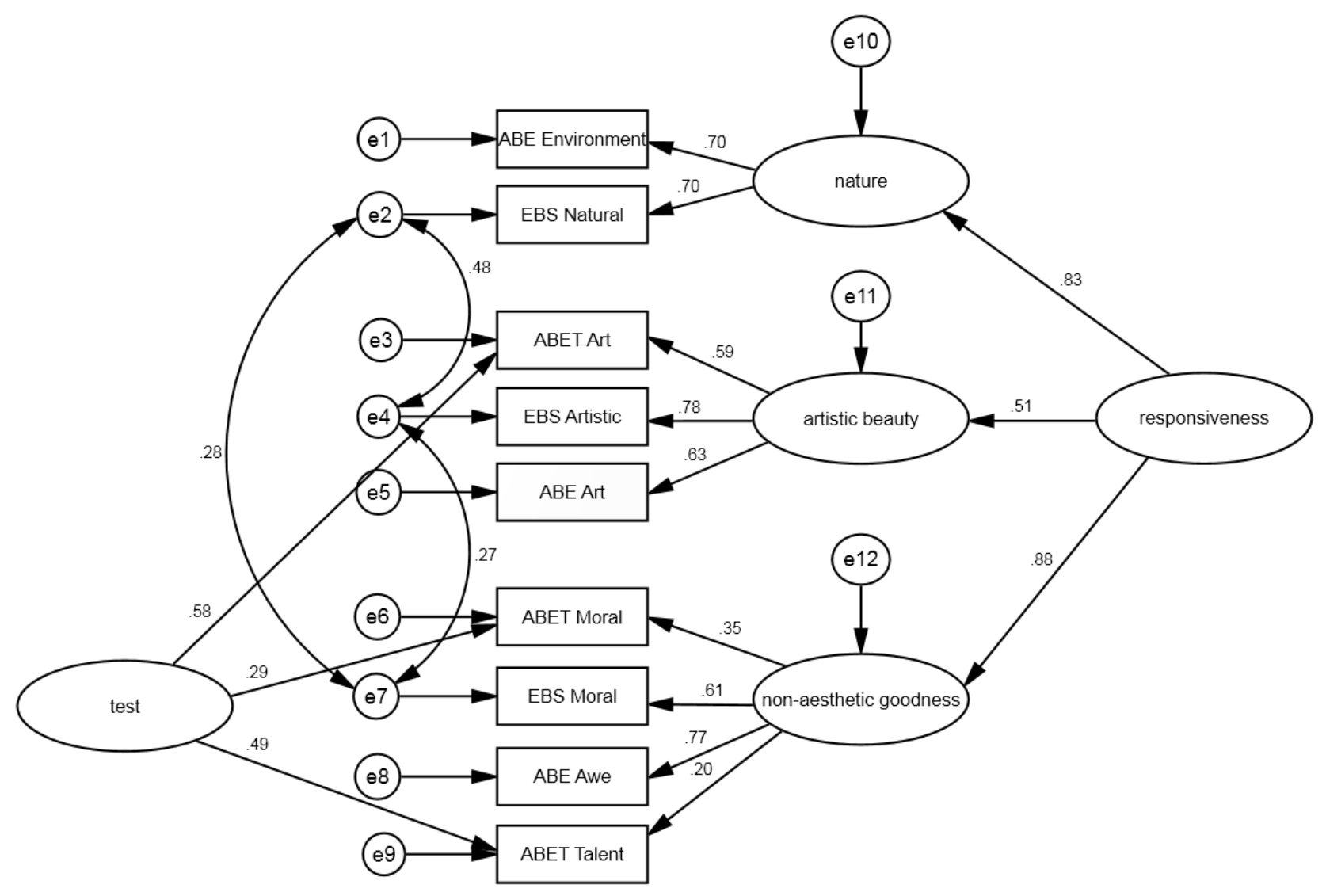

Figure 2. Final three-dimensional structural equation model of responsiveness, standardized solution.

Note. $\mathrm{N}=439$, no missings. 
Appendix A. Structure of Appreciation of Beauty and Excellence (Haidt \& Keltner, 2004) and items of ABET.

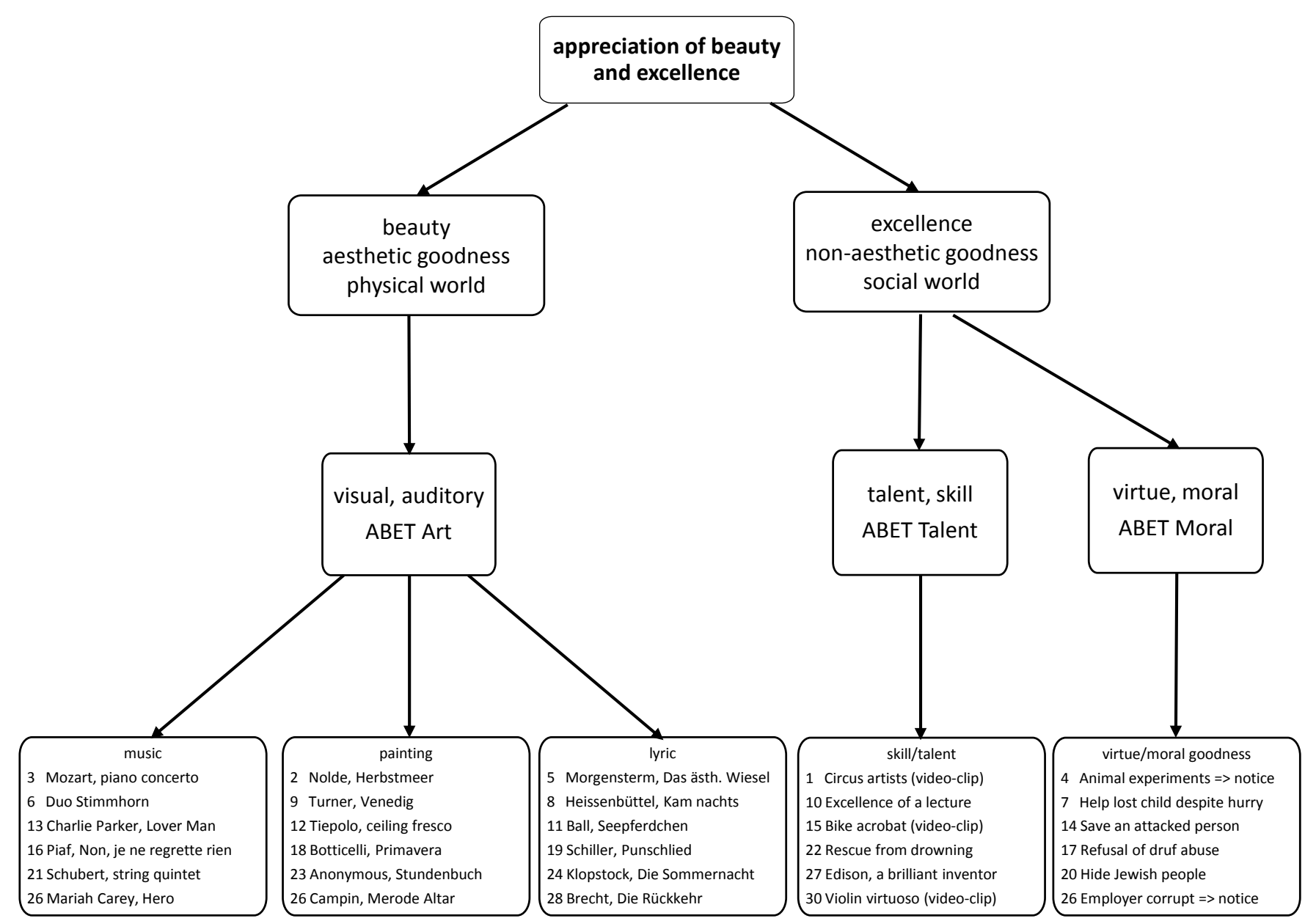


Appendix B. Unstandardized, standardized regression weights, and significance levels for Model

\begin{tabular}{|c|c|c|c|}
\hline & Unstandardized & Standardized & $p$ \\
\hline \multicolumn{4}{|l|}{ Measurement model } \\
\hline ABE Environment $\diamond$ nature & 1.000 & .704 & $\mathrm{Na}$ \\
\hline EBS Natural $\diamond$ nature & 5.307 & .703 & $* * *$ \\
\hline ABET Art $\diamond$ artistic beauty & 1.000 & .587 & $\mathrm{Na}$ \\
\hline EBS Artistic $\diamond$ artistic beauty & 8.749 & .783 & $* * *$ \\
\hline ABE Art $\diamond$ artistic beauty & 1.217 & 627 & $* * *$ \\
\hline ABET Moral $\diamond$ non-aesthetic goodness & 1.000 & .349 & $\mathrm{Na}$ \\
\hline EBS Moral $\diamond$ non-aesthetic goodness & 9.853 & 609 & $* * *$ \\
\hline ABE Awe $\diamond$ non-aesthetic goodness & 1.316 & .772 & $* * *$ \\
\hline ABET Talent $\diamond$ non-aesthetic goodness & .474 & .202 & $* * *$ \\
\hline ABET Art $\diamond$ test & 1.000 & .583 & $\mathrm{Na}$ \\
\hline ABET Talent $\diamond$ test & 1.000 & .487 & $\mathrm{Na}$ \\
\hline ABET Moral $\diamond$ test & .722 & .288 & $* * *$ \\
\hline \multicolumn{4}{|l|}{ Covariances } \\
\hline $\mathrm{e} 2 \Leftrightarrow \mathrm{e} 7$ & & .282 & $* * *$ \\
\hline $\mathrm{e} 4 \Leftrightarrow \mathrm{e} 7$ & & .273 & $* * *$ \\
\hline $\mathrm{e} 2 \Leftrightarrow \mathrm{e} 4$ & & .480 & $* * *$ \\
\hline \multicolumn{4}{|l|}{ Structural Model } \\
\hline artistic beauty $\diamond$ responsiveness & .533 & .506 & $* * *$ \\
\hline non-aesthetic goodness $\diamond$ responsiveness & .806 & .881 & $* * *$ \\
\hline nature $\diamond$ responsiveness & 1.000 & .835 & $\mathrm{Na}$ \\
\hline
\end{tabular}

Note. $N=439$, no missings. 